\title{
Retrofitting High-Tech Systems in Land-based Aquaculture to Improve Production Efficiency: An Automated Expert System Architecture
}

\author{
N. G. P. C. Mahalik \& Kiseon Kim
}

To cite this article: N. G. P. C. Mahalik \& Kiseon Kim (2014) Retrofitting High-Tech Systems in Land-based Aquaculture to Improve Production Efficiency: An Automated Expert System Architecture, IETE Technical Review, 31:2, 153-161, DOI: 10.1080/02564602.2014.892752

To link to this article: http://dx.doi.org/10.1080/02564602.2014.892752

曲 Published online: 03 Jun 2014.

Submit your article to this journal $\pi$

Џll Article views: 57

Q View related articles $\longleftarrow$

View Crossmark data $\nearrow$ 


\title{
Retrofitting High-Tech Systems in Land-based Aquaculture to Improve Production Efficiency: An Automated Expert System Architecture
}

\author{
N. G. P. C. Mahalik ${ }^{1}$ and Kiseon $\mathrm{Kim}^{2}$ \\ ${ }^{1}$ Department of Industrial Technology, Jordan College of Agricultural Sciences and Technology, California State Universoty, Fresno, \\ California, USA, ${ }^{2}$ Communication and Sensor Network laboratory, School of Information and Communication, Gwangju Institute of \\ Sciences and Technology, Gwangju, Republic of South Korea
}

\begin{abstract}
This paper presents work on retrofitting of high-tech systems (HTS) in land-based aquaculture system for improving production efficiency. The objective is to develop architecture for an automated system for aquaculture farming. We call this development an automated expert system architecture (AESA). The article has been organized into four parts. First, it reviews the background and business opportunity on aquaculture, which includes fish and seaweed farming. We have proposed a six-layer model for the development of a fully contained total automation system along with approaches and methods. The developed software platform was tested with a laboratory based demonstration rig.
\end{abstract}

Keywords:

Aquaculture, RAS, DCS, Technology systems, Expert system, Automation architecture.

\section{INTRODUCTION}

It is estimated that world food production needs to be increased by $60 \%$ by 2050 to feed 9 billion inhabitants [1]. Further, it has been reported that $23 \%$ of the world's population lives within $100 \mathrm{~km}$ distance of the coast and that population densities at the coast are about three times higher than the global average [2]. Fish and seaweeds are the two main seafood types. Aquaculture-based farming is not new; however, because of the advent of technology, this sector foresees the growth of technology-driven production systems. Although aquatic farming has been taking place for more than a millennium, on the global scale it is still a young sector of food production and the world has seen significant growth in the last 60 years. Aquaculture plays an important role in food production, which is constantly growing because of increasing demand since 1970. Captured and aquaculture-based fish production was roughly about 150 million tons (MT) in 2010 and 2011. Out of these, about 130 MT in each year was used as food and remainder in industrial applications such as fish oil, cosmetics and food for animals. The total monetary value of $100 \mathrm{MT}$ of fish is about US $\$ 150$ billion [3]. Worldwide annual production of seaweed is about 6 MT with a value of around US $\$ 5-6$ billion [4-6]. The world number of fish farmers is estimated to be 17,000 (medium to large) and the approximate total number employed in the fisheries sector has increased from 30 to 60 million in the past
20 years. Farm production has been constantly expanding in the last 40 years with an average annual growth rate of $7.5 \%$. It has been the supply-demand curve that has inspired farmers to apply new methods and techniques to produce more seafood per annum. The technical variations in cultivating seaweeds depend on species, local conditions and experience. For example, emerging techniques such as integrated multi-trophic aquaculture [7] are gaining popularity because of the its symbiosis in nature and because it meets consumer demand. Fish and fishery products represent a very valuable source of protein and essential micronutrients for balanced nutrition and good health. An average person receives 25\% of their animal protein from fish (75\% from other food). The fish itself contains $15-20 \%$ protein and most of fish are rich in vitamins A, B and D. Similarly, seaweed contains protein, minerals, vitamins, fibre, etc. (Figure 1) [8].

\section{TECHNOLOGY REVIEW: AQUACULTURE APPLICATIONS}

Currently, there are intensive fish farming processes on the coast and in the ocean. The objective is to grow fish in a controlled environment. In open ocean the average cage measures $15 \times 15 \times 5 \mathrm{~m}$. Fish species like milkfish, pompano, seabass, lapulapu and snapper are preferred. However, there are several ocean cage farming issues, such as pollution and environmental influences. In cage farming, rubbing of fish on the cage sides damages fins 


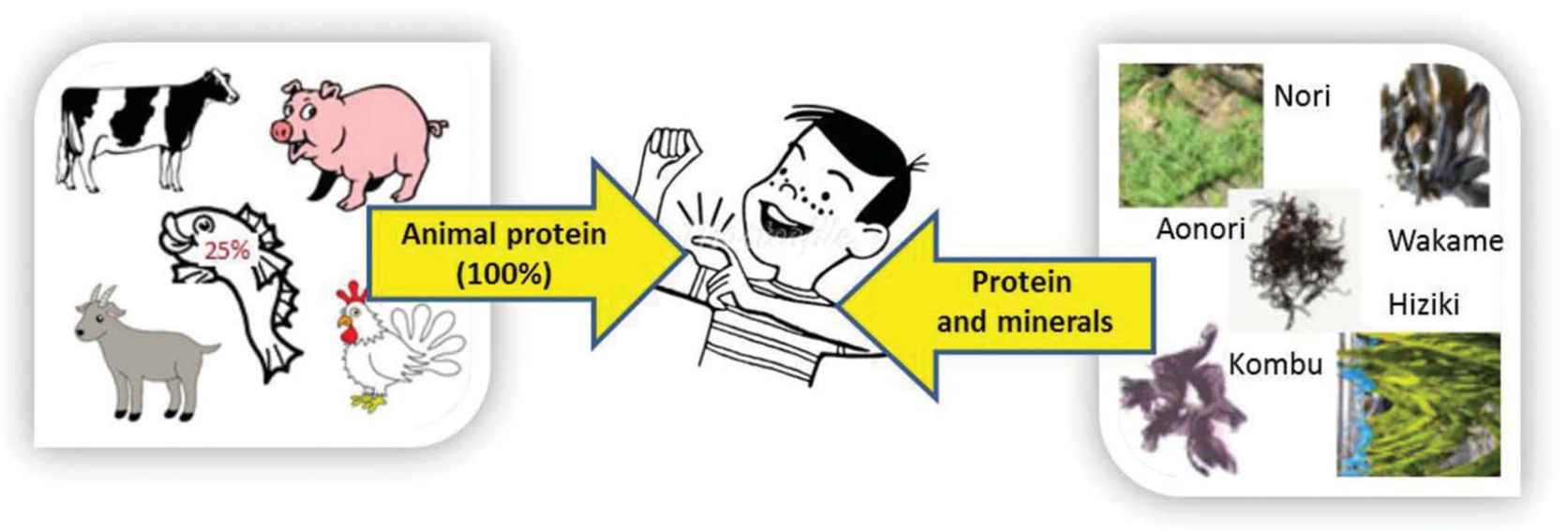

Figure 1: Twenty-five per cent of animal protein comes from fish. Fish itself contains $20 \%$ protein. The five types of commonly harvested seaweeds are nori (30-50\% protein; $0.1 \%$ sugar; vitamins $A$ and $C$, niacin and folic acid; amino acids; low $\mathrm{NaCl}$ ), aonori (20\% protein; vitamins; minerals; low fat and $\mathrm{NaCl}$; high $\mathrm{Fe}, \mathrm{Ca}, \mathrm{Mg}$; used for flavouring), wakame (vitamins $\mathrm{B}$ and $\mathrm{K}$; fucoxanthin; $\mathrm{Mg}, \mathrm{Ca}, \mathrm{Cu}, \mathrm{Co}, \mathrm{Ni}, \mathrm{Zn})$, kombu (10\% protein, $2 \%$ fat, moderate level of vitamins $\mathrm{A}$ and $\mathrm{C}$; high in iodine; kombu broth, tea, soup) and hiziki (similar to kombu; phlorotannins removed before eating; inorganic arsenic; fibre; $\mathrm{Mg} / \mathrm{Ca}=1 / 2)$.

and tails. As a result, a good percentage of fish become sick with various diseases and infections. Also, the process germinates sea lice and parasites, which in turn transfer disease organisms from wild fish to the aquaculture fish and vice versa. The farmer needs to obtain various permits and water-use rights near the seashore because it belongs to the public and government. The entire operation is labour-intensive.

Aquaculture-based farming will advance the local as well as global economy [9]. A report by Food and Agricultural Organization (FAO) of the United Nations documents that GIS (Geographical Information Systems) and remote sensing technology and tools will advance more sustainable aquaculture. It mentions that a challenge lies with geographic cognition and spatial awareness that will continue to cause significant spatially variable effects on marine and other aquatic environments, and these effects can be best managed through the application of GIS and remote sensing methods. As a part of the design documents of the aquaculture environmental monitoring program (AEMP) for the Nova Scotia marine aquaculture industry, a standard operating procedure, a series of sampling instructions, laboratory guides, and field templates that are designed to assist farm operators have been released based on recent advancements in science and technology [10,11].

In fish farming the implications of technology have already been demonstrated [12]. Application of technology in seaweed aquaculture has not yet been researched. Currently, there are no value-added processes introduced to the seaweed farming. The farming process includes establishment of the farm, harvesting, replanting and maintenance. Drying and packing are taken care of by the production unit. The site where production takes place controls the quality index, which is the dryness of the product, which is subsequently shipped in packed bags in containers to advanced countries [13].

However, technology can play a major role in both cases. Low-cost technology-driven aquaculture systems will significantly improve the productivity and the controlled environment will reduce adverse environmental impacts. Affordable manpower to maintain the farms is an indispensable prerequisite. Personnel at all levels of skills play a vital role for overall profitability. Note that more than $50 \%$ of the seaweed labour force is unskilled and semiskilled. A minor error in heuristic-based monitoring and regulation of growth can cause a significant annual loss, which there can be a threat to the business. The business can grow if there is a technology-driven solution to cultivation and production process lines.

Closed, recirculating aquaculture systems (RAS) are used to raise fish and are advantageous as commercial operations. RAS systems provide a high potential for waste removal and treatment and avoidance of escape and predation problems. The research team at Baltimore [12] has demonstrated a fully contained landbased RAS and the system viability was validated by growing gilthead seabream (Sparus aurata) from 61 to $412 \mathrm{~g}$ for a total of 1.7 tons in a record 131 days with 99\% fish survival. The demonstration included system performance and multiple benefits that drive its 
economic feasibility as a viable alternative for the production of high-quality seafood with minimal environmental impact. The oxygen, oxidation-reduction potential (ORP), ozone, $\mathrm{pH}$, temperature, salinity and evaporation rate were continuously monitored and maintained at the desired level. However, system design needs to meet the cost-performance ratio. An economically competitive fish RAS technology system should entail approximately $\$ 0.50 / \mathrm{kg}$ per year of system capacity production. Reducing the costs of production in RAS technology is paramount and the various components of the systems need to be addressed. Further, RAS is still a semi-manual operation, because the fish are manually fed. There is no variable feeding operation, as the fish grow. The growth rate calculation, called feed conversion ratio (FCR), is not automated. Other important parameters that have not yet been considered for monitoring are disease, agility, optical properties, nutrients and sedimentation. The current RAS system needs improvement in a recirculating loop. The management of large-scale RAS is complex because it entails measurement of a large number of parameters. Let us formulate a scenario of a 10 storey aquaculture building, with 1000 tanks, each containing 10 tons of water. For such a huge system we need about 20 pumps, 2000 valves and equivalent feedback control drive systems (Figure 2). There would be 10,000 data-logging (monitoring variables) points to measure $\mathrm{CO}_{2}, \mathrm{O}_{2}, \mathrm{O}_{3}, \mathrm{TAS}$, TAN, temperature, $\mathrm{pH}$, light, disease and bacteria, and about 1000 variable feeding systems, 250 filter cleaning systems and finally 1000 automations of $\mathrm{CO}_{2}$ strippers and protein skimmers. For such a system, high technology equipment with larger dimensions on many fronts is needed.

RAS-based fish farming involves three cost factor components: fixed costs (tank, water, food, pump, valve, pipes, etc.), labour costs and variable costs (depend on many factors - if fish dies, it affects the feeding rate, the quantity of food consumption will be low, hence the total cost for a production cycle will decrease). Fixed costs are about $20 \%$ of investment. The difference is reflected in other two. The labour cost is increasing steadily at a rate of $3-5 \%$ (Figure 3 ) and

\section{High-tech system: Fieldbus, DNAC, DCS/SCADA, HMI, Internet, PDA}

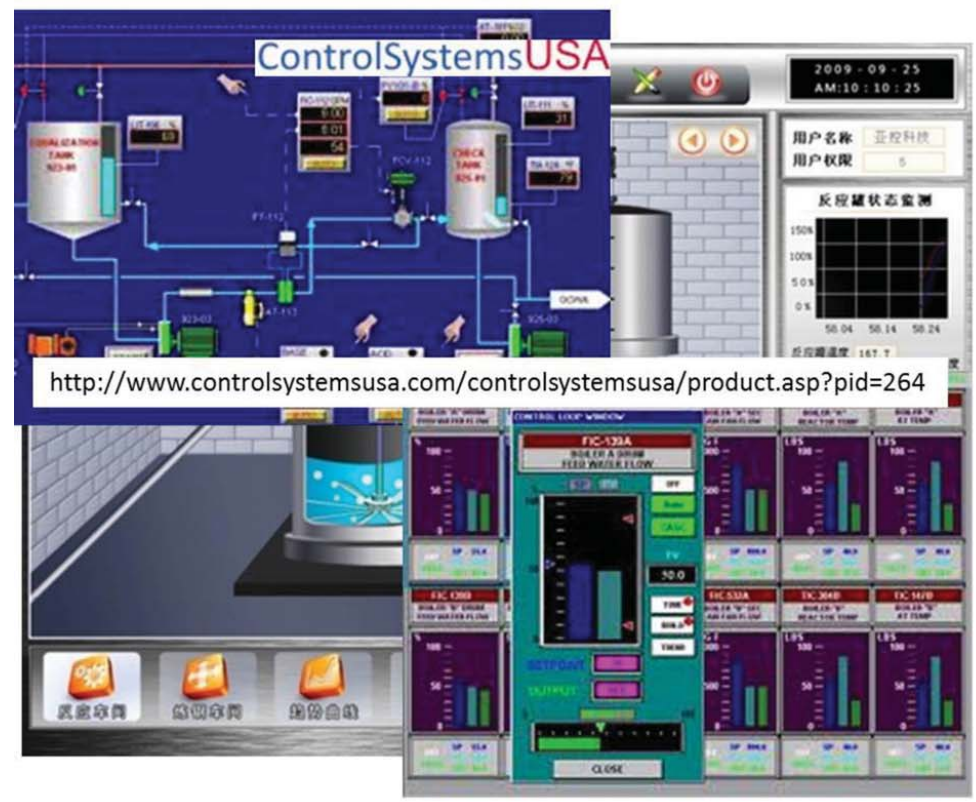

Fully contained; Total automation
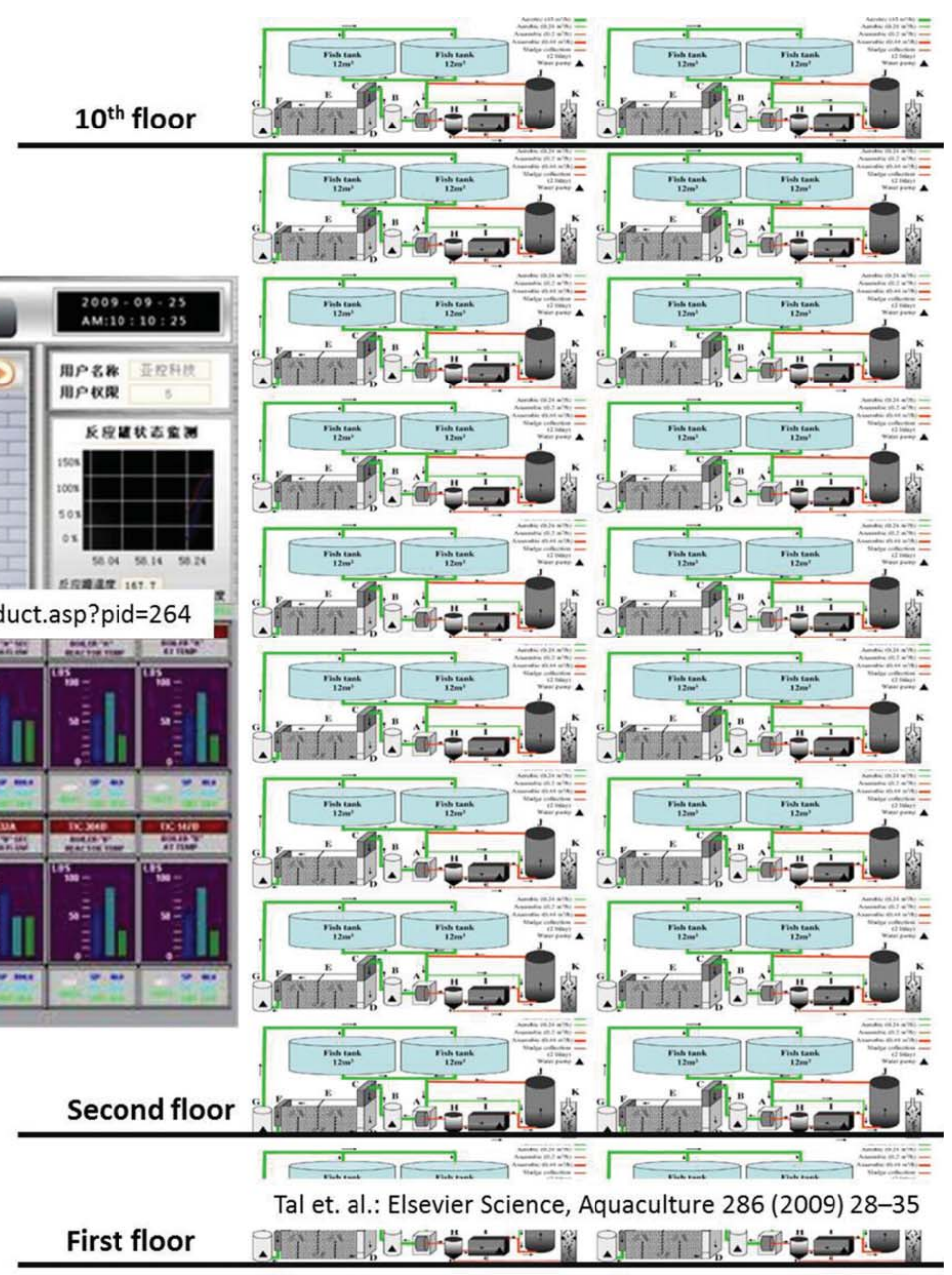

Figure 2: The futuristic modern aquaculture system for vertical farming. 


\section{AESA}

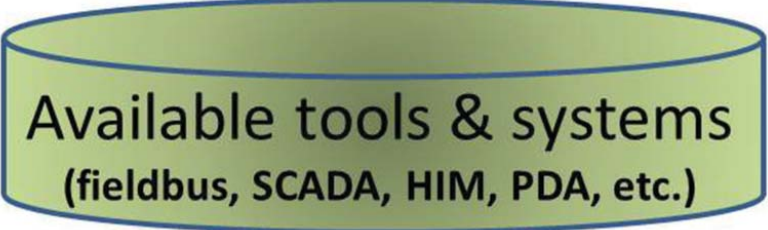

RAS

Figure 3: Automatic expert system architecture.

there is a trend of shortage of labour because the world is progressing towards being business-oriented. In the future we may not see labour but business-labour. Recently, the net aquaculture profit margin has reduced by $50 \%$ compared with a decade ago dowing to labour costs. Also, as mentioned, the availability of skilled labour and technical specialists is a factor. Using technology, the labour cost can be significantly reduced. Similarly, significant savings can be achieved through the variable costs, which include optimal life span, FCR and survival rate. Looking into these gaps we have proposed an automated expert system that is capable of handling aquaculture systems not only from a monitoring and control prospective, but also system validation, supply chain management, and overall productivity. For example, the proposed expert system can automatically calculate the FCR and regulate the feed rate, direct which fish group (tank) to use based on fish density owing to differential growth, control light (energy), water, $\mathrm{O}_{3}, \mathrm{O}_{2}, \mathrm{pH}$, etc. precisely, and provide demand-supply analysis in a second.

Although fish and seaweed farming have different setups, in the latter, the usable technology systems are considered to be a subset of the former. For example, seaweed farming does not require a tank-based precise recirculating system; however, both types of farming need a light control system. Even if farming seaweed is not considered a tough job, there is an incredible numbers of variables involved which are beyond the control of humans. To be productive, the farm should be well attended. This means that farmer constantly visits and checks it. One of the main factors is that seaweeds grow very rapidly and the constant effort required is a challenge. Further, there are thousands of different kinds of seaweed. The minimum water salinity required is about $28 \mathrm{ppt}$. The seaweed needs to be kept clean while growing. In order to do this, the farmer has to shake or raise the seaweed lines to remove any unwanted seaweeds and rubbish, else, the growth and hence the productivity will be significantly reduced. Cleaning is a tedious procedure and vital to seaweed farming, otherwise other seaweeds will take away the nutrients necessary for the seaweed of interest and the plantlets will not grow well. Further, some parts of the plant always obstruct the growth of the neighbouring plant for which reason they need to be removed from the platform to the shore. Continuous monitoring of those parts is important to improve productivity. Because of currents and other factors, lines become detached. The broken lines should be fastened and lost plants replaced. Yield mapping is important to differentiate quality of seaweed at the cultivation stage. The biggest enemies of seaweeds are fish grazers. They should be monitored and driven out through technology implementation. Optimal harvesting time is critical to production. Seaweed should be harvested as soon as it reaches its optimal size. Over-grown plants break and drift away. Also, overmatured plants are difficult to dry as their branches are thicker. Onsite determination of optimal growth can be achieved through technology systems. Note that, by precisely controlling the light, the growth rate can be increased by up to $400 \%$. Other controlling parameters are $\mathrm{O}_{2}$, $\mathrm{O}_{3}$, salinity and turbidity. Above all, both platforms require a high-tech supply chain management system, which is the focus of this paper.

\section{METHODOLOGY AND DEVELOPMENT}

For aquaculture, low tech with semi-manual operation is neither optimal nor safe because of contamination, pollution and hazard. An incredible amount of data and operation management is necessary when we think about a large system. Distributed networked automation and control (DNAC) with common datalogging systems for all input/output devices such as actuators, sensors, valves, switches, etc., with SCADA (Supervisory Control and Data Acquisition) type technology systems are proven technology for such a large-scale system. SCADA systems are usually used for drift irrigation, oil sector, power/energy delivery, etc. Integration of the latest HMI (human-machine interface) based interface will enhance remote operation and control. Fieldbus such as PakBus, DNP3 or LonWorks can facilitate DNAC implementation. Fieldbus have SCADA and HMI features. Finally, Internetbased system operation is needed because remote operation using RF media is necessary. One of the important technical features is interoperability. Portable devices such as iPOD, iPAD and iPhone can be interfaced, utilizing their email features so that the global system operation and management is possible. Additional traceability including supply chain management (just-in-time delivery system) benefits can be 


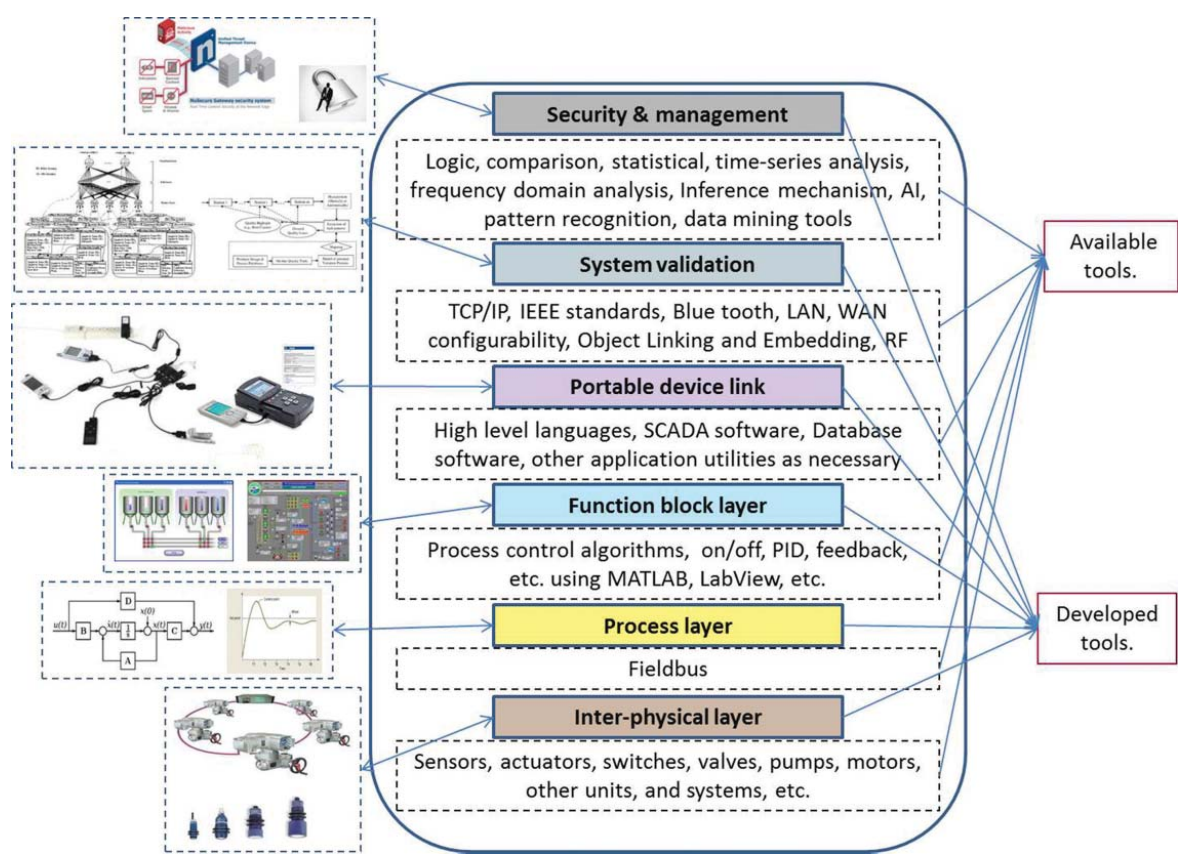

Figure 4: The proposed AESA layers. AESA is a six-layer architecture (inter-physical layer, process layer, function block layer, portable device link and user layer, system validation layer and services, and security or management layer).

achieved through RFID technology. Considering all these features, we have proposed an automatic expert system architecture (AESA) for RAS, which resides on the top of the available tools and systems (Figure 3). Even though fieldbus, DNAC, SCADA, HMI, Internet and PDA systems are available in the market place, the proposed AESA for RAS can be thought of as a six- layer architecture: inter-physical layer; process layer; function block layer; portable device link and user layer; system validation layer and services; and security or management layer, as illustrated in Figure 4. the AESA has three modules: field-device Module, energy and infrastructure module and management module as shown in Figure 5. The AESA layer services are

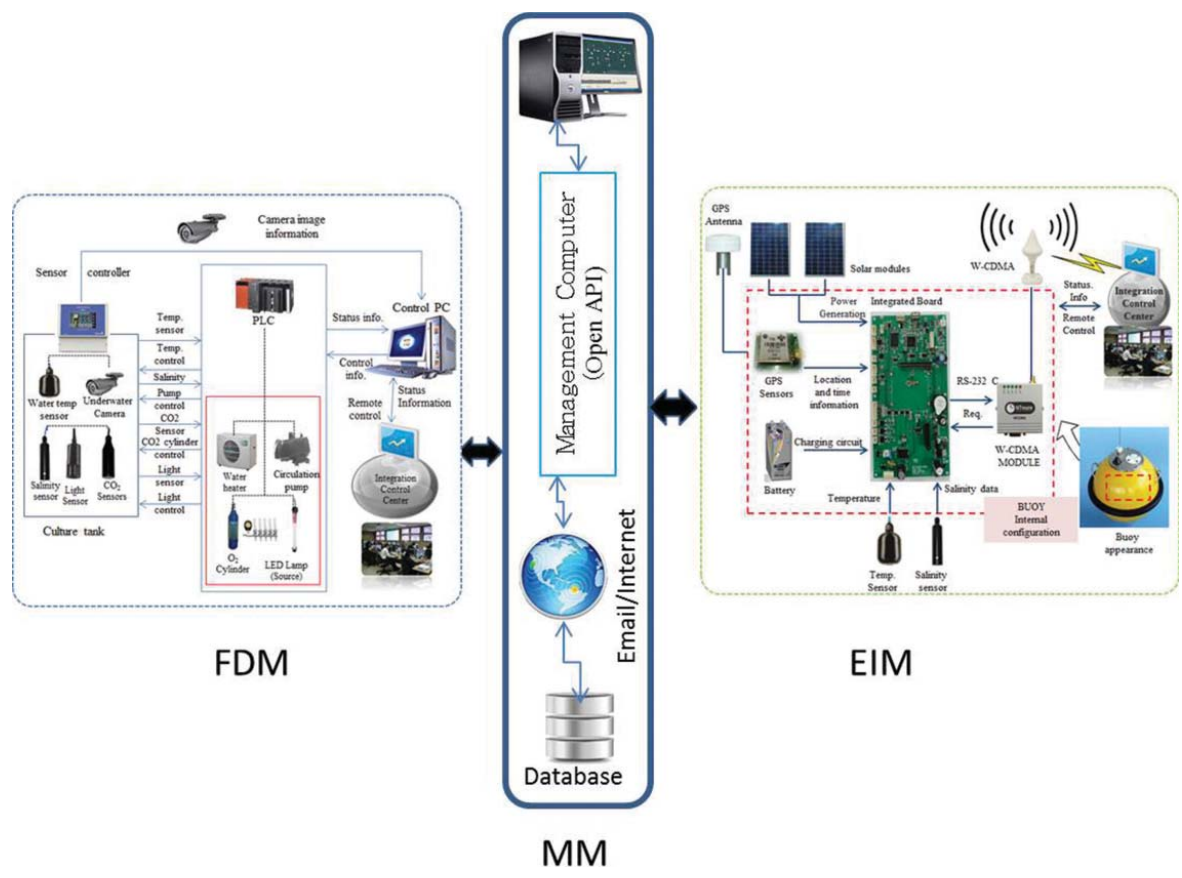

Figure 5: Proven and stable hardware technology, backup system and intended product configuration. 
Table 1: AESA layers and services

\begin{tabular}{|c|c|}
\hline Layers & Services/features \\
\hline \multirow[t]{2}{*}{ Inter-physical } & $\begin{array}{l}\text { Design and development of generic but modular physical and electrical interfaces of all RAS-purpose sensor and } \\
\text { actuator units }\end{array}$ \\
\hline & $\begin{array}{l}\text { Selection of appropriate toxic-, humidity-, salinity-resistant materials for coating, covering and protecting the electronics } \\
\text { and instrumentation }\end{array}$ \\
\hline \multirow[t]{7}{*}{ Process } & Development of off-line process (OLP) model using modelling tools \\
\hline & Development of centralized database system \\
\hline & Development of various process algorithms \\
\hline & - Feedback control for pump and valve controllers \\
\hline & - Sensor, actuator, and other process objects as necessary \\
\hline & Interfacing procedure and methods for OLP with the process objects \\
\hline & Documentation for the users \\
\hline \multirow[t]{4}{*}{ Function block } & Configurable virtual system \\
\hline & Off-line design \\
\hline & Connection verification \\
\hline & System validation and optimization \\
\hline \multirow[t]{7}{*}{ Portable device link } & Linking and embedding \\
\hline & Database link object \\
\hline & Internet, intranet, RF objects \\
\hline & Interface objects \\
\hline & Interoperable objects \\
\hline & Configuration objects \\
\hline & Variable and parameters objects \\
\hline \multirow[t]{4}{*}{ System validation } & Comparison of the acquired data with the look-up table data at all levels for self-validation in real-time \\
\hline & Autocorrection of the process at the system level \\
\hline & - Implementation of analysis algorithm by the use of soft computing tools and methods \\
\hline & - Data mining approaches \\
\hline \multirow[t]{7}{*}{ Security and management } & Graphical user interface design using objects \\
\hline & Supply chain management applications \\
\hline & Just-in-time, bills-of-materials, ordering interfaces \\
\hline & Retrieval of data/parameters per requirement \\
\hline & Remote monitoring and control because of sudden changes \\
\hline & Alarming \\
\hline & Security and username \\
\hline
\end{tabular}

distributed and integrated across all the modules to build a holistic architecture. Table 1 provides the services of each of the layer followed by a description.

\subsection{Inter-physical Layer}

The inter-physical layer interfaces between the field devices such as sensors and actuators with the fieldbus. There is no standardized interface available for this purpose. The proprietary fieldbus manufacturers develop their own modules for user-defined purposes. In many situations, the users buy off-the-shelf separate input/output interfaces to accomplish the purpose. Sometimes users buy extra components and building blocks already integrated in a proprietary interface module. We have consolidated the common types of input/output interfaces and signalling as applicable to RAS expert systems. Figure 6 shows the architecture of the inter-physical layer schematically.

\subsection{Process and Function Block Layer}

Most of the available field devices such as sensors and actuators are compatible with analogue or digital signalling methods for communication. Commonly used analogue current and voltage are 4-20 mA and varied voltage levels, depending of the application requirements. The users then perform calibration and

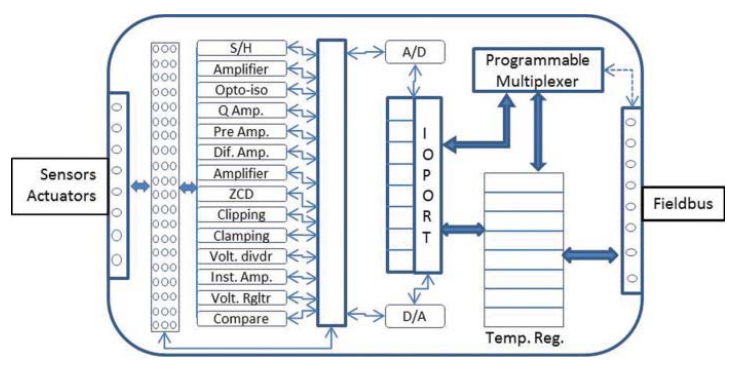

Figure 6: Inter-physical layer. 
interface them with the fieldbus nodes individually. A fieldbus node is a node that has four entities: the processor, network transceiver, executable control code, and input/output interface port. Sometimes a centralized controller is used instead of fieldbus or other backbone system. However, our objective is to adopt DCS (distributed control system) philosophy using fieldbus-type technology for expert system-based RAS automation. Part of the process layer defined in this architecture is to facilitate calibration of most RASrelated sensors. The other part of the process layer is to provide algorithm-level user interfaces to build control codes for the DCS nodes. For example, a motor needs to be controlled speed-wise for process automation. We have defined this service as an actuator calibration (CA). The CA also includes on-off, proportional, proportional-integral-derivation and other process entities.

The function block layer can be considered as an offline design module of the architecture. It is capable of performing both non-temporal and temporal simulation of part and the entire automation system for RAS prior to its installation, called the building phase. The services include virtual system configuration, off-line design, connection verification, system validation and resource optimization. The layer is a solution to "think-ahead" proactive design. The approach can help to shorten the design-to-validation cycle by enabling the users to correct errors and to identify optimized design ingredients and even acceptable temporal parameters and requirements. The final design benefits from such an assisted optimization service prior to its prototype testing followed by real design. It also closes the design loop by enabling design, validation, comparison with other data, diagnostics and refinement functions. The service eventually validates and optimizes the entire design and development. The process and function layers are built into one module (from software point of view). A snapshot of this module at one point is shown in Figure 7.

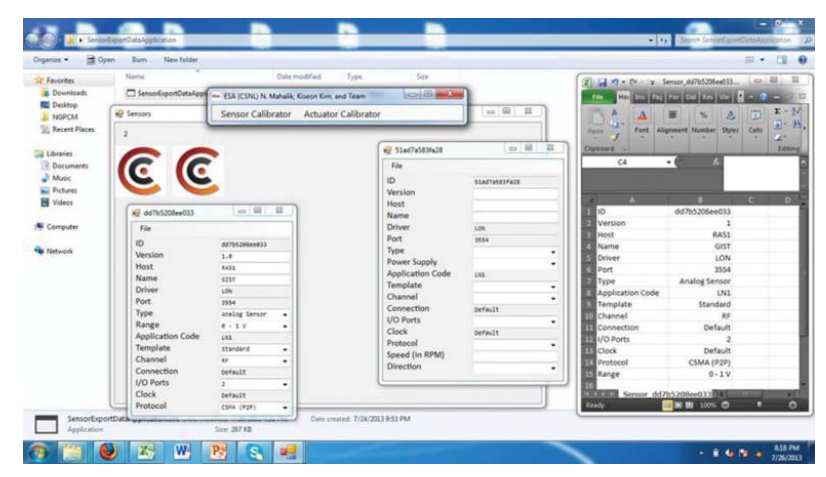

Figure 7: A snapshot of sensor and actuator calibrator.

\subsection{Portable Device Link Layer}

Managing automation using GSM (Global Systems for Mobile) based wireless control system is quite possible. Not only switching-type operation, but several management functions, such as timer setting, speed control and remote display, are achievable. Further, the customer can check the status of the product (fish/seaweed) location in the supply chain (loading to delivery). The feed-forward order-supply system can easily be regulated and automated. This is achieved via a link layer service. Through integration of global GSM technology, this layer provides control solutions at one end and supply chain management system at other end. The two sublayers have a common kernel. The kernel operates based on standard SMS (Short Message Service) linking and standardized protocols.

\section{IMPLEMENTATION AND TESTING}

Fieldbus-based DCS implementation is best as it can handle both physical and radio communication. More than 25 fieldbus-technology systems are available for process monitoring and control applications. Among them Profibus, P-NET, HART, ModBus, LonWorks, CAN and DeviceNet are used for different application domains. We used a LonWorks system to test individual field devices in our feasibility study. Our inter-physical layer is compatible with fieldbus technology. Devices such as sensors and actuators and monitoring and control building blocks were successfully tested individually and in a network. For demonstration, a testing scenario is shown in Figure 8.

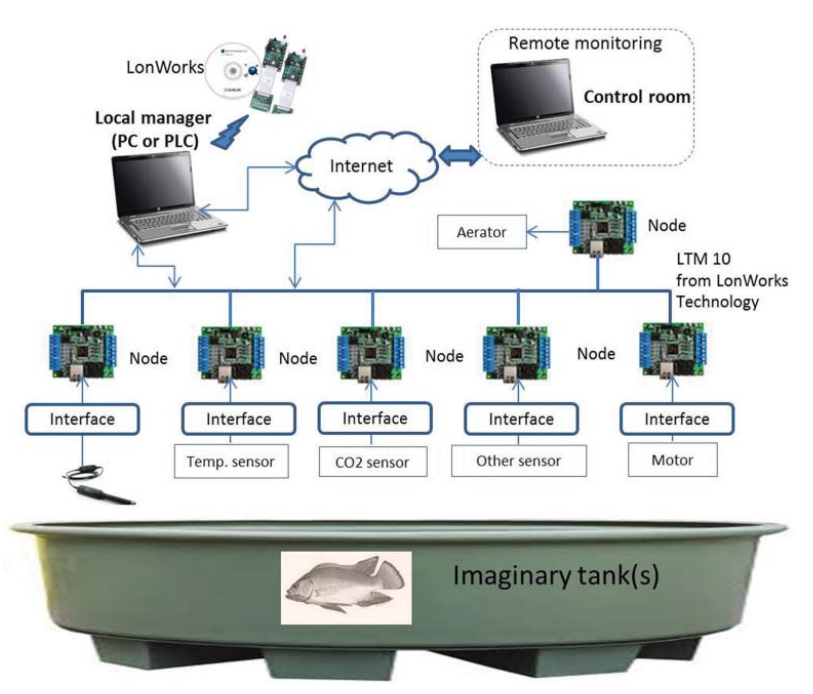

Figure 8: (a) Experimental setup containing node (from LonWorks); (b) a level detector incorporates kalman filter algorithm to produce more accurate sensor reading. 


\subsection{Basic Nodes}

This is a basic building block of DCS architecture. Each sensor and actuator should have a node attached to it. In its basic form it has a microcontroller, input/output ports, transceiver, memory and power supply unit. LTM10 from LonWorks technology can be used for developing a node. We have tested LTM10 and it has all the technical ingredients to serve as a node for an RAS system. For example, it can connect to analogue and digital, sensors of various current and voltage ranges and has compatible radio and network solutions. LonWorks technology provides code development and a network kernel to calibrate, program and integrate the devices seamlessly. A node should not cost more than US\$10 (excluding licence).

\subsection{Testing of Sensors and Calibration}

We experimented with the node to various types of sensors such as temperature, dissolved oxygen, camera, $\mathrm{CO}_{2}$, infrared, light, encoder (to monitor the speed of the motor/aerator), level detector, hall-effect sensor (to be used in motor/pump to monitor the condition) and pyroelectric sensors. The minimum requirement of dissolved oxygen is about $4 \mathrm{mg} / \mathrm{L}$. Fish may die at less than $2 \mathrm{mg} / \mathrm{L}$. Usually, fish are immune to $10 \mathrm{ppm}$ of dissolved carbon dioxide provided dissolved oxygen concentration is high. The concentration fluctuates from $0 \mathrm{ppm}$ in the afternoon to $7-12 \mathrm{ppm}$ at dusk. Note that in RAS the concentration is always higher, sometimes exceeding $20 \mathrm{ppm}$. Therefore, continuous monitoring of carbon dioxide is vital because the high levels interfere with the oxygen utilization by the fish. In order to monitor the turbidity, a camera system can be used. The colour image is converted to grayscale images representing low dark pixels to high light pixels and is analysed and interpreted as turbidity after a few processing steps. First we wrote the code for individual sensors and downloaded each sensor's code to the node for execution and display on the computer screen via network. Several small networks were also built and tested. For example, consider a situation: "When the water level is $L$ stop the pump and run again when below $L^{\prime \prime}$. In DCS architecture, this problem can be solved by the use of three nodes: node 1 for pump, node 2 for level sensor and node 3 for display. All the nodes must be connected physically as well as logically. Physical connection is simple and usually based on available standards. The logical connection is vital for global operation, for which each node should have its own code for the way it should work and connect to another node logically. For this the developer has to write the code for each field device. The execution of the code is carried out at each node, not at field devices such as sensors and actuators. The following sensors were calibrated and stored in the database.

\subsection{Testing of Actuator}

We tested the fieldbus-based DCS nodes with actuators such as motor, pump and aerator using an AESA platform. The important control algorithms for all these actuators are start, stop, speed control, movement (forward, reverse), send and receive message/ data (to connect with sensors via DCS network). Note that actuator also sends a message to a display-node at the user-control-room to inform whether or not it is running, for example. We used a DC motor which can be configured to run the fan, aerator and pump. For DCS, each actuator has a dedicated node. For actuators, LTM10-based nodes were also used, tested and validated.

\subsection{Testing of Portable Devices}

The AESA is compatible with portable devices. For this we used iLON, a product from LonWorks Technology which connects to the Internet. The iLON has IP (Internet Protocol) and the portable devices can talk to each other and also connect to DCS nodes (for updating, management, etc.) via iLON using AESA's portable link layer service. The FB layer of the AESA was used to design the demonstration platform shown in Figure 8 off-line. During this proactive design, a database was produced. Details about the use of simulation tool for off-line design can be found in Mahalik and Kim [14].

\section{CONCLUSIONS}

This paper suggests an AESA for aquaculture monitoring and control applications. We have defined the AESA as a six-layer model. The primary goal was to develop an integrable software platform capable of embedding the proposed six layers and their services (see Table 1) so that the architecture can be used for RAS areas. We have successfully demonstrated the platform by testing it with several RAS-related sensors, actuators and portable devices. A DCS-based control philosophy was adopted in the design. The benefits of DCS have been highlighted. Bearing in mind that the proposed AESA has all the building blocks and ingredients, future work includes refining the architecture for comprehensive demonstration in a real-world aquaculture system.

\section{ACKNOWLEDGEMENT}

This research was supported by Ministry of Oceans and Fisheries, and by Leading Foreign Research Institute Recruitment Program through NRF, Korea, funded by the Ministry of 
Science, ICT and Future Planning (MSIP; 2009-00422) in Korea. The authors acknowledge the Department of Industrial Technology, Jordan College of Agricultural Sciences and Technology, Fresno State, California, USA.

\section{REFERENCES}

1. C. Nellemann, M. MacDevette, T. Manders, B. Eickhout, B. Svihus, A. G. Prins, and B. P., Kaltenborn (eds), "The environmental food crisis - The environment's role in averting future food crises." A UNEP rapid response assessment, United Nations Environment Programme, GRID-Arendal, 2009. Available: www.grida.no

2. R. J. Nicholls, P. P. Wong, V. R. Burkett, J. O. Codignotto, J. E. Hay, R. F. McLean, S. Ragoonaden, and C. D. Woodroffe, "Coastal systems and low-lying areas," in Climate Change 2007: Impacts, Adaptation and Vulnerability. Contribution of Working Group II to the Fourth Assessment Report of the Intergovernmental Panel on Climate Change, M. L. Parry, O. F. Canziani, J. P. Palutikof, P. J. van der Linden and C. E. Hanson, Eds. Cambridge University Press, Cambridge, pp. 315-56, 2007.

3. Food and Agriculture Organization, World Fisheries and Aquaculture. Fisheries and Aquaculture Department, FAO, UN, 2010.

4. M. De San, "The farming of seaweeds Report/Rapport: SF/ 2012/28," Report prepared with the assistance of EU, 2012.

5. C. R. Kaur, and M. Ang, "Seaweed culture and utilisation in Malaysia: Status, challenges and economic potential," in Seminar on Developing the Seaweed Aquaculture Sector in Malaysia, Maritime Institute of Malaysia, 2009.
6. C. M. Buchholz, G. Krause, and B. H. Buck, "Seaweed and man," C. Wiencke and K. Bischof, Eds. Seaweed Biology, Ecological Studies 219. Berlin: Springer, chapter 22, 2012.

7. A. Butterworth, "Integrated multi-trophic aquaculture systems incorporating abalone and seaweeds," Nuffield Scholar, Australia, 2009.

8. Available: http://www.fao.org/docrep/field/003/ac287e/ac287e01. htm

9. Manta Consulting Inc., "Financing aquaculture, investment opportunities in farmed seafood," Technical paper, Finance Briefing Paper Series, Issue 2, 2009.

10. Nova Scotia, "A standard operating procedures for the environmental monitoring of marine aquaculture under Nova Scotia aquaculture environmental monitoring program," Nova Scotia Fisheries and Aquaculture, 2011.

11. G. J. Meaden, and J. Aguilar-Manjarrez, Eds, "Advances in geographic information systems and remote sensing for fisheries and aquaculture," FAO, Technical Paper, 2013.

12. Y. Tal, H. J. Schreier, K. R. Sowers, J. D. Stubblefield, A. R. Place, and Y. Zohar, "Environmentally sustainable land-based marine aquaculture," Aquaculture, Vol. 286, pp. 28-35, 2009.

13. M. Kronen, "Socio-economic dimensions of seaweed farming in Solomon Islands," Secretariat of the Pacific Community, Aquaculture Division, Food and Agricultural Organization with cooperation with Ministry of Fisheries and Marine Resources, Aquaculture, Honiara, Solomon Islands, Jan. 2010.

14. N. P. Mahalik, and K. Kim, "A prototype for hardware-in-theloop simulation of distributed control architecture," IEEE Trans. Systems, Man Cybernet. Pt C, Vol. 38, no. 2, pp. 189-200, 2008.

\section{Authors}

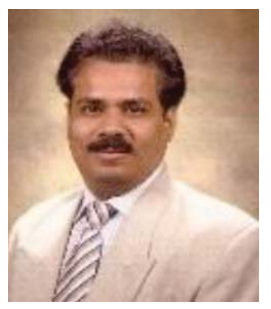

Nitaigour Mahalik is Associate Professor and Chair in the Department of Industrial Technology, Jordan College of Agricultural Science and Technology, California State University, Fresno, USA. Professor Mahalik was awarded a PhD from De Montfort University, UK in 1998. He has published 60 journal papers and given about 100 presentations. Professor Mahalik has guided more than $60 \mathrm{MS}$ thesis/projects and five $\mathrm{PhD}$ theses. Professor Mahalik has written and edited five technical books on automation and control, mechatronics, fieldbus technology, and sensor networks. He served as editor-in-chief and guest editor in several international journals. Professor Mahalik is an IEEE member.

E-mail: nmahalik@csufresno.edu

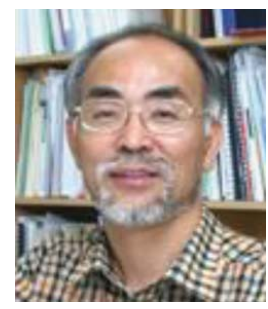

Kiseon Kim received BEng and MEng degrees in electronics engineering, from the Seoul National University, Seoul, Korea, in 1978 and 1980, and a PhD degree from the University of Southern California, Los Angeles, in 1987, in Electrical Engineering-Systems. From 1988 to 1991, he was with Schlumberger in Texas as a senior development engineer, where he was involved in development of wireless telemetry systems. From 1991 to 1994, he was a computer communications specialist for the Superconducting Super Collider Laboratory, in Texas, where he built detection and analysis systems for large-scale instrumentations. He joined Gwangju Institute of Science and Technology, Korea, in 1994 as a Professor. His current interests include wideband digital communications system design, sensor network design, analysis and implementation both at the physical layer and at the resource management layer. Professor Kim has guided $40 \mathrm{PhD}$ and $70 \mathrm{MS}$ students, and published about 250 articles.

E-mail: faith.kskim@gist.ac.kr 